\title{
Art in the Era of Postmodernism
}

\author{
Maria Matyushova \\ Peoples' Friendship University of Russia \\ Moscow, Russia \\ E-mail: maria_matushova@mail.ru
}

\begin{abstract}
The article deals with the philosophical interpretation of the tendencies taking place in contemporary art. The author shows that the main aesthetic category of contemporary art is the category of novelty.
\end{abstract}

Keywords-Contemporary art; postmodern; the category of novelty; scandal as an aesthetic category

\section{INTRODUCTION}

The profound processes taking place in modern society could not pass by such a culture as art without having an impact on it. Since romanticism, there has been a review of the main categories of art in the direction of subjectivism, and this process of change has affected the subject of artistic creativity - the Artist, the work of art, and the specificity of aesthetic perception.

It is quite difficult to answer the question what contemporary art is because of historical and methodological reasons. First, it is necessary to determine which historical interval marks "modern art". Today, there are two perspectives on this issue. One of them sees the examination of contemporary art from the Impressionist art, i.e. from the end of the XIX century and up to 60-70 years of the XX century, and mentions modern directions such as Dadaism, Futurism, Cubism, abstractionism, although they have long since ceased to exist.

Another point of view, based on modern artistic practices, considers only those processes in art "modern" that are characteristic of our time. It argues that the term "modern" refers to art, which stems from the 60-70-ies of the XX century and lasts until our days. This is the most common point of view, often used by art historians. It is based on the fact that it was in those years that the term "Modernism" and "Postmodernism" appeared.

Because of this, it is difficult to determine some chronological framework for contemporary art. That is why it should be about the qualitative characteristics of the art.

The difficulty in determining the art of postmodernism lies in the fact that it is very diverse and eclectic. The eclecticism of modern art is manifested by the fact that the works of artists show an unusual combination of materials and methods. Finding a single organizing principle to work out a single objective criterion to accurately determine what contemporary art is and to bring all this diversity into some kind of Categorical apparatus, is very difficult.
Indeed, how can one combine such different trends under one name as pop art, conceptual art, happening, installation, neo-dada, art graffiti, body art, video art, etc.? How can we unite the work of Andy Warhol and Yaya Kusama, the artistbusinessman Damien Hirst and Emin Tracy? How can we combine the dead sheep in formaldehyde (D. Hurst), a portrait of the Virgin Mary "painted" with an elephant litter (K. Ofili) and a white room with one flashing electric light bulb (M. Creed)?

Most contemporary artists working in a postmodern manner reject the very idea of a clear definition of art as a form of activity and a form of reflection of reality; to explain the activities of various artists, they use phrases such as "artistic pluralism" which means acceptance and existence of various artistic practices. Representatives of postmodern constantly emphasize that for the creation of a work of art, new ideas and concepts are more important than the level of mastery of an art object.

\section{CATEGORY OF NOVELTY}

The main category of aesthetics, which characterizes the art of modernism and postmodernity, is the category of novelty. Novelty is an attribute, a sign of the creation of genius, and here it does not matter in what form this novelty is manifested. The phrase "modern art" is understood as something "new", innovative, which until then did not exist. Novelty becomes the goal of creativity and the criterion of value. There is a cult of novelty, a cult of an unusual form of an art object. In this sense, the artistic value of the work, directly perceived by us, recedes into the background behind the demand for something new. Neither the taste, nor the special talent of the artist, nor his true eye, capable of capturing the beauty of the surrounding world, play a big role, and the concept of "inspiration" is not fashionable and has practically already left the lexicon of the modern artist.

The ratio "artist-spectator" has changed as well, because the viewer plays an active role in the process of building the meaning of the work of art. Some artists claim that the modern viewer himself makes sense in the work, or even completes the work of art, relying on his personal experiences and reflections; he gives his interpretation to the work.

The traditional judgment of the recipient "I like" or "I do not like" is now replaced by thinking about what is being depicted, what the author wanted to say and what the idea of the art object is, i.e. the emotional assessment is replaced by 
reflection and description. However, following this approach, we not only lose the communicative function of art, but also lose track of the aesthetic criterion applied to art - the criterion for determining a good or a bad art object.

Thus, in judgments about art, we come to extreme subjectivism, individualism, nihilism and reject any normativity. There are no absolute truths and no outstanding, talented or mediocre art, because all "truths" have the right to exist. The subject of art is subjectivity itself, which expands to infinity and is ontologized; the following of some canons and values is replaced by a slogan - "I myself create values that are important to me".

In this regard, U. Eco speaks about the need to introduce the concept of "open" work of art, which should be applied to art. If art is intended to meet the needs of the modern world, it must be open in its approach to the world. Art should not bind itself once and for all to established norms, as it was inherent in normative aesthetics, but create and explore a picture of the world that is no longer tied to rigid models. An "open" work of art contributes to the recognition of a particular freedom within the viewer or reader and encourages him to form his own model of the world. [1. P.22].

\section{SCANDAL AS AESTHETIC CATEGORY}

If we speak about contemporary art, it is impossible to circumvent such phenomena, which fundamentally characterize its essence. We mean the role of the scandal in art, the new form of attracting the attention of viewers to a work of art. The term "scandal" comes from the Greek word "skandalon", which means "stumbling block". This stumbling block in the modern world are events associated with scandalous exhibitions, when the public demands the prohibition of these exhibitions, scandals related to the copying of classical masterpieces, forgery and their sale at well-known auctions. In these cases, the main task of the artist is to provoke the reaction of the public: to encourage the audience to react and to pay attention to a work of art, and, most likely, to its author. It does not matter whether this is a positive reaction, or, on the contrary, a negative or shocking one.

There are many examples from the world of contemporary art that shock an unprepared viewer. For example because blood is used as a material for an installation (Mark Quinn, a member of the group "Young British Artists", chose this unusual material for a self-portrait) or even natural human waste. What do these examples say? Only one thing: if art becomes a commodity, then to it, as well as to any product, advertising is necessary. Advertising here is not only the very unusualness of the "work of art", but, above all, the provocative behavior of the artist himself, the scandal. He plays such a big role in the fate of the work of art today that this phenomenon can be identified as a new aesthetic category for disciplines studying art: in our time the artist is ready to go to anything only to be noticed, challenging society, shocking the viewer and, in general, society, balancing, sometimes, on the verge of legality. Moreover, representatives of these kinds of actions deliberately seek to shock the public, and consciously commit these actions, which can be attributed to abnormal behavior - to eccentricity and deviance. An image of a rebel artist is created; a man of deviant behavior, violating all taboos,

The examples from the world of art allow us to make the conclusion that today great success and recognition of an artist as outstanding depend on whether paintings are sold well; contemporary art is not obliged to internal factors, i.e. not artistic merits of the work. The "success" largely depends on advertising and raising a scandal that the press or television reports about, i.e. purely external factors.

The scandal has turned into a stable norm from the form of deviant behavior of the artist; only in this way, artists can attract attention in the world of ever disappearing "masterpieces" of art. In this sense, Marcel Duchamp, whose direct heir is Demien Hirst, provoked a scandal during the First World War using objects from everyday life - a bottle holder, a bicycle wheel, and a urinal - the status of works of art. Demien Hirst took the next step: he took living creatures as material for his creativity and places them in the artistic space.

The apotheosis of scandal was the British exhibition of works in 1997, called "Sensation", under the auspices of the Royal Academy of Arts. Speaking about the new art, the curator of the exhibition, Norman Rosenthal, calls "to conquer new territories, to destroy taboos". "He compares their frank sensational treatment to the problems of the present day (sex, drugs, murders, etc.) with the gesture of Edward Manet, who instead of the naked heroine of myths and legends portrayed a prostitute "Olympia" lying on a luxurious bed" [2. P. 180].

Analyzing these phenomena, we can conclude that contemporary art fundamentally changes the perception of the relationship between beauty and ugliness, showing the relativity of the two concepts. Artists do not just aesthetize the ugly, but put it on a higher pedestal than the pedestal of beauty. There is a cult around Ugliness that expels and replaces the previous tradition, which focused on Beauty. Explaining this phenomenon, many theorists refer to the fact that the world itself has changed so much that the criteria for artistic values have changed as well; that there is so much ugliness in the world itself that the old canons can no longer serve as a guide in art, and as an artist, you must display this in your creativity. In addition, the weightiest argument that confirms the existence of these phenomena in art is the assertion that once in a society there is moral relativism and nihilism in relation to traditional values, this leads to aesthetic relativism and aesthetic nihilism automatically. Consequently, this leads to a replacement of the beauty in life and in art by factors, which are ugly, shocking, disgusting, etc.

Art becomes a game, which is independent of the artist's forces and the century-old image of the artist is destroyed. Formerly, the artist devoted his life to art, sacrificing his well-being and the welfare of his loved ones for the sake of the idea of artistic immortality. Now, that we have the truth that there is no good and bad in art, the artistic consciousness 
falls into a deep art crisis, from which it is unlikely to be able to escape. Just like religious faith, which helps a believing person to overcome unimaginable obstacles in order to save his soul, the artist's faith in his exceptionality and his will to preserve his artistic individuality allowed him to overcome the unbearable burdens of life such as misunderstanding, poverty and loneliness. After the traditional idea was destroyed in the understanding of true and false art, true creativity lost its meaning. As a religion is impossible without God, art is impossible without Genius. Genius cannot be created artificially through advertising or excitement, and a person who feels "Genius" is forced to simply quit the game, because to him, creativity was not just a game, but a service to those divine forces that he felt in his soul.

However, the XIX century and more so the twentieth century changed many things. The concept "Genius" disappeared almost from the vocabulary of arts critics and was replaced by the term "Author" (Roland Bart, Michel Foucault), and the term "work of art" was replaced by the word "project" or "artifact". The project is a composite product; it is the combined effort of the artist, the gallery owner, the advertisement, the curator, the dealer. In this composite product, the artist's own work occupies an insignificant part. As the contemporary literary critic, Boris Groys, says, the whole thing is in the gesture of the artist, who decides to transfer an item to the exhibition space. It is through this that the object becomes a fact of art. Consequently, according to Groys, the essence is not what is exposed, but who first decided to recognize a certain object as a fact of art, and first took it to the museum.

\section{CONCLUSION}

What conclusion have we reached? A very ambiguous one - to paraphrase Plato's famous expression "Beautiful is difficult", one can say that it is difficult to determine what art in the modern era is. The concept of art has almost merged with the concept of life, however, in its most negative aspects. The answer to the question if a garbage dump is art depends on where this so-called art object is located; if in a museum, it is a work of art, if on the street the answer will be different. This is what Dickey, the author of the institutional approach to the definition of art, writes in his famous article "Defining Art". He argues that the art of the twentieth century became the same social institution as politics, business and science. Therefore, we should not evaluate the aesthetic qualities of a work of art, but a group of people involved in the art world should act on behalf of a certain community (artists, critics, art critics) and if they recognize the object as an artifact, then place it in a museum or theater and this will be seen as a work of art.

Modern art has far removed from traditional functions such as cognitive, educational and aesthetic. It has ceased to be a means of cognition, a kind of mirror reflecting reality in its essential features, and has ceased to induce creativity and develop the best qualities in humans. In general, postmodernism rejects the idea that art can make sense. The basic premise is if life does not make sense, then even more, this statement applies to art - so let us not pretend that art can make men or society better. Let us just admit that it is absurd, like everything else, and we are done with it.

Art, more and more, is associated with a game that is alien to pathos and seriousness, and the idea of devoting oneself to art, to sacrifice one's life for the sake of "great art" is viewed with irony by many artists. Even more, a "great work of art" can be created without much work within a day, an hour or simply as something picked up on the road. A quality such as artistic arrogance is taken for artistic genius.

The processes that have occurred and are happening in art in recent decades are reminiscent of the artificial breakdown of the natural historical process and contradict the main line of cultural development, which is directly related to the image of Man, the Beautiful, and the Truth [3]. Art throughout its long history was defined as "human studies", for it was man, his thoughts, feelings, hopes, experiences that were at the center of the reflection of artists and writers. Outstanding works possessed the ability to capture the soul and imagination of the viewer, without the thousands of words that postmodernism needs to explain the meaning of what is depicted on the canvas. These works exerted a tremendous influence on the hearts and minds of people, contributed to the spiritualization of man, his breakthrough into the world of transcendence, and was not only understood by Plato in the classical era of antiquity, but also by Kant and Hegel in the Age of Enlightenment.

\section{REFERENCES}

[1] Eco U. Openness of the work of art // Some problems of modern foreign aesthetics. Sat. Translations and abstracts. In 2 parts M., 1976. Part 2.

[2] Arutyunova A. Art market in the XXI century. Space of artistic experiment. M., 2015.

[3] Chistyakova O.V. Postmodernism, Christian Patristics, and Values of Peace in the Modern Cultures In the Context of Educational Process // Proceedings of the 2016 International Conference on Arts, Design, and Contemporary Education. Volume 64 (ICADCE 2016) Advances in Social Science, Education and Humanities Research. Atlantis Press. - Paris. France. 2016. ISSN 2352-5398. P. 996-1000 